Near finalised version of:

A M Williams, 'International labour migration and tacit knowledge transactions:

a multi-level perspective', Global Networks 7(1): 1-22

\title{
INTERNATIONAL LABOUR MIGRATION AND TACIT KNOWLEDGE TRANSACTIONS: A MULTI-LEVEL PERSPECTIVE
}

Allan M Williams

London Metropolitan University

UK 
INTERNATIONAL LABOUR MIGRATION AND TACIT KNOWLEDGE TRANSACTIONS: A MULTI-LEVEL PERSPECTIVE

\begin{abstract}
There has been limited research on the role of international migration in the transfer of tacit knowledge, as opposed to skills and capital. In part, this results from lack of engagement between research on migration and that on knowledge and learning, even in debates concerning the relative importance of distanciated versus localised knowledge transfers. However, positioning international migration in relation to the literature on knowledge management opens up new perspectives on its role in the overall transfer of knowledge in the economy. Starting from the premise that all tacit knowledge transactions are socially situated, this paper sets out a multi-level approach to understanding the role of migrants in knowledge exchanges. The national, the urban and the firm constitute key levels in this analysis, although these are understood as inter-folded rather than as discrete sites of analysis.
\end{abstract}




\section{INTRODUCTION (A heading)}

While both human migration and knowledge/information are recognised as key dimensions of globalization (Held 2000), there is surprisingly little research about how these are interwoven, and, in particular, how international labour migration contributes to tacit knowledge transactions. Most obviously, international migration reconfigures corporeal co-presence, or brings about face-to-face relationships that can facilitate tacit knowledge transactions. Of course, migration is only one means for achieving corporeal co-presence. Koser and Salt (1997: 299) argue that 'if physical mobility is required to make ... expertise mobile, it may range in duration from a few hours in a workshop, to a few months on a placement, to long term migration'. Changes in technology, transport and knowledge management mean that different forms of mobility have become increasingly substitutable (Salt and Ford 1993: 27). Tacit knowledge can also be shared electronically, leading Amin (2002) to argue that localized and distanciated relationships may be interwoven. Despite these caveats, international migration is increasing in scale, and changing in composition, constituting an important, but little researched, channel of tacit knowledge transactions. Tacit knowledge transactions are understood here as all forms of inter-personal knowledge exchanges and learning.

This paper seeks to make two contributions to this research field. First, it examines how the lack of understanding of the role of international labour migration in tacit knowledge transactions is largely the product of limited engagement between research on these two phenomena, which have been driven by very different conceptual and empirical approaches (see also Williams 2005).

Secondly, it argues that labour migration and tacit knowledge transactions have to be understood as situated in particular places, a notion that chimes with concepts of 'situated learning' (Brown and Duguid, 1991), and 'domainspecific knowledge' (Hodkinson et al 2004: 11) in the literatures on knowledge creation, transfer and management. However, this paper does not advocate focussing exclusively on particular places, abstracted from the wider contexts that shape migration. Rather, there is a need for a multi-level perspective that recognises three key sites that shape the contribution of international migration to knowledge transactions: the national, the regional, and the workplace. Moreover, these are seen as inter-folded.

The conclusions reflect on the conceptual and the challenges for taking forward a research agenda that would explore, both theoretically and empirically, the relationships between international migration and knowledge.

\section{MIGRATION AND KNOWLEDGE (A)}

The limited cross-fertilisation between the literatures on migration and knowledge partly reflects the focus of migration research on skills rather than knowledge, while knowledge research focuses on tacit versus codified 
knowledge, and on the management of knowledge transfers. But there are also different disciplinary alignments, with migration researchers looking more to economics (notably human capital theories) than to management studies, which is the main locus of knowledge transactions research. This section of the paper examines some of the more relevant, but largely disconnected, research themes in migration and knowledge, as a starting point for developing a multi-level perspective on their inter-relationship.

\section{Migration, human capital, and knowledge (B)}

There has been considerable research on the transfer of skills by labour migrants, especially within the framework of human capital theories, and this is being extended to a broader understanding of skills and competences. However, relatively little attention has been given to the role of migrants in knowledge transactions. This lacuna was especially evident in earlier research on mass migration. More recent research on skilled or highly-skilled migration has paid more explicit attention to knowledge issues but is highly selective, largely being concerned with intra-company mobility and the role of migrants in knowledge-intensive industries. However, all employed migrants have potential for knowledge transactions, especially if companies are understood as 'constellations of distributed know-how and reflexivity' (Amin and Thrift 2002: 61). Here we consider human capital theories, mobility in transnational companies, and the role of migrants in knowledge intensive industries.

Human capital theories view labour migration as an investment decision in which expected returns are balanced against costs, including risk and uncertainty (Sjaastad 1962). Typically, quantitative methods are used to measure the relationships between individual socio-economic characteristics, migration intentions or behaviour, and returns to migration. Given the data requirements of these models, education is usually used as a surrogate measure of human capital. While more refined measures of education and skills can be incorporated in these models, none encompasses the complexities of tacit knowledge (see below). Findlay et al (1996) recognized this in their advocacy of the concept of total human capital. There have been few attempts to operationalize or develop this concept, although Williams and Baláž (2005) have employed Evans' (2002) 'starfish' model of five basic competences, to explore a range of social as well as technical skills acquired by Slovak migrants to the UK. However, human capital research does not engage with migrants' knowledge transactions per se.

Nevertheless, the human capital literature is useful because it has addressed temporality issues. The central argument is that increased time spent in the destination country is related to the acquisition of country-specific skills that are positively correlated to income (Duvander 2001). Language skills are particularly important in this respect (Dustmann et al 2003). This recognizes that knowledge is socially situated, and that migrants have to acquire placespecific knowledge if they are to valorize fully other forms of knowledge. 
The literature on transnational companies and highly skilled mobility is informed by the premise that mobile, 'knowledgeable' or 'learning' individuals are important in knowledge transfer (Bunnell and Coe 2001: 581-2). Salt and Findlay (1989) outlined the need for a new conceptual framework for skilled migration, identifying a threefold typology of mobility: transfers within transnational companies, international contracting of staff to work abroad, and recruitment by international agencies. While the last of these has belatedly been researched (Ward 2004), intra-company mobility has received most attention.

Intra-company mobility is one area where the migration and management literatures overlap significantly. Nevertheless the role of different types of mobility, including human migration, in knowledge transactions within transnational companies remains imperfectly understood. A number of surveys (for example, NOP Business/Institute for Employment Studies 2002) have shown that companies value international migration as a means to foster cultural diversity and redistribute international expertise across their branch network. However, as Sakai's study of Japanese banks in London demonstrated, the resulting knowledge transactions can be complex, contested and deeply compromised.

Some of the more interesting research in this field has stemmed from several projects involving Beaverstock and co- researchers. For example, Beaverstock (2005: 246) focused on transnational managerial elites in New York's financial services district as an example of how 'epistemic communities' (Thrift 1996) mediate flows of information, capital and skills between global cities. Transnational experiences were valued by individuals as contributing to career development because they facilitated the accumulation of intellectual and social capital. Research in London, Singapore and other world cities has confirmed the importance of such knowledge transactions to both the individuals and companies, whilst exploring different workplace and social arenas in which these are situated (for example, Beaverstock 2002). Whilst recognizing that knowledge is socially situated, this approach necessarily is narrowly focused on higher-level management and professionals.

Another strand of research has examined the contribution of international skilled migrants to knowledge-intensive industries. This is partly rooted in macro-economic modeling of the impacts of migration on output or employment (for example, Dustmann et al 2003); knowledge transactions are only implicit in such studies. However, there is also a more qualitative strand of research. This is most highly developed in iconic high tech areas, such as Silicon Valley, where immigrant workers played a key role in innovation: 'a flexible industrial system in a knowledge based industry depends on a flexible immigration system that allows the continuous arrival of workers with the newest skills and ideas' (Alarcon 1999: 1395). While Silicon Valley is probably exceptional, it has informed other national and regional projects to assemble critical masses of 'idea generation' (Lucas 2001), via recruitment of highly skilled-scientists and engineers, many of who are migrants. There are also policy discourses about how countries of origin can capture migrant 
knowledge, either through return migration or other means of reverse knowledge transfers (see Hess 2004 on the relationship between Taiwan and Silicon Valley). Such studies assert the importance of migrants and returned migrants in knowledge transactions, but there is little analysis of the exchanges, or the social situatedness of knowledge.

As the above summaries indicate, migration research that, at least implicitly, considers knowledge transactions, has been limited in scale and fragmented. While human capital theories potentially embrace all types of migration, recent research has been selective, focussing on what may be termed elite (knowledge-intensive) occupational groups and territories. This can be further illustrated by considering how research is focussed on bounded versus unbounded mobility, specific temporalities, and types of jobs/skills.

First, in terms of boundedness (in the sense of migration within constrained frameworks), research has mainly focused on intra-company moves. Yet there are industries, for example hotels, where inter-firm mobility far surpasses intra-firm mobility, reflecting a different balance between internal and external labour markets (Ladkin and Riley 1996). Additionally, there are extra-firm movers who migrate to a destination area without formal or informal employment contracts with local firms, constituting 'free agent labour migrants' (Williams 2005). These differences are critical because intra-, interand extra-firm migrants are potentially involved in different, and varyingly predictable, types of knowledge transactions. Secondly, there have been complex changes in the temporality of migration, with a shift from longer-term to shorter-term mobility and circulation (King 2002). This is important because there are different time horizons for acquiring particular types of knowledge, whether linguistic, technical or social. Yet there has been relatively little systematic research on these different types of migrant experiences, or on returned migration as opposed to emigration.

Thirdly, migrants' knowledge transaction experiences are highly job specific, even amongst the highly skilled. For example, Mahroum (1999) identified a five-fold categorisation of mobility: managers and executives; engineers and technicians; academics and scientists; entrepreneurs; and students. Because of differences in migration duration, job content, and the organizations within which they work/study, these groups have different experiences of knowledge transactions. The dominant focus on business professionals and intracorporate transfers means such diversity has not been captured in existing research (Nagel 2005). This diversity is even greater, if other types of migrants are considered. Neither unskilled migrants, nor migrants in unskilled jobs, have knowledge-free experiences. In many cases, their status or their jobs are socially constructed as unskilled, whereas they may utilise high levels of skills and knowledge; this is often related to the gendering of migrants' employment (Raghuram 2004). Even migrants working in routine jobs - such as fast food outlets - are involved in some knowledge transactions that we have little understanding of.

This last point resonates with the emphasis in the management literature on knowledge being diffused throughout companies (Hodkinson et al 2004), that 
is the need to look beyond the managerial level. It also chimes with the emphasis in the skills literature on 'social skills', such as competence in communication, or team working, that is skills which are required in most jobs (Payne 2000). The next section considers these issues from the perspective of research on knowledge.

\section{Knowledge and knowledge transfers (B)}

Knowledge is a slippery concept, as illustrated by three approaches outlined below. First, Polanyi (1966) identified the classic division between tacit and explicit knowledge. Tacit knowledge is that which the user is not easily, or not at all, able to express in explicit forms. Later researchers explored different forms of tacit knowledge, and Blackler (2002) summarises this in the distinction between embodied, embrained, encultured, and embedded knowledge (see also Williams 2006). Later research challenged this classic approach. Yang (2003) considered that knowledge is understanding about reality through mental correspondence, personal experience, and emotional affection with outside objects and situations. Hence, there are three interrelated facets of knowledge - explicit, implicit, and emancipatory (or emotional affection). And Styhre (2004) argued that the distinction between tacit and explicit knowledge is a false problematisation because, in practice, they are inseparable. Instead, knowledge is an assemblage of cognitive capacities, within which intellect and intuition represent different forms of thinking. Moreover, knowledge is 'always an unstable, fluid, rather elusive capacity to know, to do, to think things'. (185)

These three contrasting definitions place different emphases on the importance of emotion and intuition, and also on the fluidity of knowledge. But they do concur that different ways of knowing, and different types of knowledge, are inter-related. This paper argues that a number of implications for labour migration follow from this reading of knowledge.

Some forms of tacit knowledge transactions may be realised at a distance, via electronic communication, but others are more effectively, or perhaps only, achieved through co-presence. This can be expressed in terms of the three approaches to understanding knowledge. In respect of Blackler's (2002) review, embodied and embrained knowledge are fully exchangeable via corporeal mobility, which in some instances is a necessary condition for such transactions. In contrast, there are significant barriers to transferring encultured and embedded knowledge, because these are grounded in shared understandings (see Williams 2005), and are socially situated. In terms of Yang's typology, migration is critical to acquiring emancipatory knowledge, because normally this can only be developed through corporeal co-presence. Finally, the relationship of migration to Styhre's emphasis on a fluid relationship between intelligence and instinct is less clear but, arguably, intuition may be shaped by corporeal co-presence. Irrespective of how knowledge is understood, paying greater attention to international migration can enrich the literature on knowledge transactions. This is illustrated by three considerations. 
First, the knowledge management literature emphasises the importance of organizations' intra-, inter- and extra-firm networks (Nohria and Ghoshal 1997). But, surprisingly, this literature has largely ignored the role of international labour migration (for example, Easterby-Smith and Lyles 2003; Hodkinson et al 2004). On the one hand, the knowledge advantage of foreign ownership has long been recognized (Hymer 1960), and is mirrored by substantial research on intra-company mobility within transnational companies, as indicated earlier. However, the inter-firm and extra-firm mobility that characterize inter- and extra-firm networks, have only been cursorily researched, as have the multi levels at which these operate.

Secondly, international migrants are potentially significant as knowledge brokers. Building bridges across boundaries, between different communities, is an important source of new perspectives (Wenger 2000). Boundaries can be constituted in many different ways, but international migration traverses boundaries that have juridical, cultural, and -sometimes - professional meaning (for example recognition of qualifications). Individuals are potentially significant knowledge carriers both as migrants and returned migrants, although the opportunities and barriers they face at different levels mediate this.

Thirdly, 'knowledge is learned and accumulated through personal and social life experiences ..... being shaped by both personal inner factors and outside environmental factors' (Yang 2003: 108). This chimes with the notion of lifelong learning, expressed by Beckett (2000: 41) in terms of the experience, knowledge and skills that individuals draw on from all areas of their lives, and not only from paid employment. This biographical perspective reinforces the importance of a multi-level perspective on migration that looks beyond the immediate workplace at how knowledge is socially situated, and has changed over time for individuals.

This section of the paper has outlined some of the ways in which research on international migration and knowledge has or, more frequently, has not been inter-related. At the same time, the review indicates some fruitful area for cross fertilisation of research. The next section of the paper outlines some key elements that - taken together - provide a multi-level perspective on the socially situated nature of knowledge. This is also a framework for integrating research on tacit knowledge transactions and migration.

\section{A MULTI-LEVEL PERSPECTIVE ON SOCIALLY SITUATED KNOWLEDGE} (A)

Amin (2000), and others, argue that economies need to be understood as flows and networks that transcend and reconstitute the meaning of territoriality and borders. However, these flows - including migration - are embedded in particular places. Massey (1994: 154) expresses this in terms of places being constituted of 'articulated moments in networks of social relations' and, critically, argues that such networks involve both localised and distanciated relationships. That view links to recent debates on knowledge transfer 
concerning the relative importance of localized relationships, based on faceto-face propinquity, versus distanciated relationships, facilitated by electronic communication (Amin 2002: 393). This paper contends that international migration has largely been ignored in such relationships even though, if proximity is important in tacit knowledge transactions, migration may be a necessary condition to effect this under some circumstances. But migration also reshapes distanciated relationships. Migrants bring with them social networks (Meyer 2001) and migration itself can transform what had been localized networks or relationships in the place of origin into distanciated ones in the destination. Hence migration reproduces and reshapes both localized and distanciated relationships. In practice, these outcomes are not easily predictable because the '... fit between specific kinds of migrants and specific local and national contexts abroad' shape the nature of transnational ties (Guarnizo and Smith 1998: 13).

The last point about specific local and national contexts emphasises the situatedness of learning and knowledge transfer (Brown and Duguid 1991). The key, as Blackler (2002: 63) argues, is that "knowing should be studied as practice, and practice should be studied as activity that is rooted in time and culture'. This paper concurs but it also stresses the need to adopt a multilevel perspective on how the role of migrants in knowledge transactions is socially situated.

A multi-level approach can be specified in different ways. For example, Kloosterman and Rath (2001) identify the national, the regional/urban and the neighbourhood as key sites of influence on opportunity structures for immigrant entrepreneurs. However, in examining international labour migration and tacit knowledge transactions, this paper argues that they key sites are the national, the regional and the firm:

- Despite globalization tendencies, the national remains a key site for regulation of migration, particularly in respect of immigration and employment, but also the national innovation system.

- The regional level is significant because many of the institutions that shape learning in firms are articulated at the regional level. Regions are also the level where migration intersects with the dynamics of local labour markets, localised inter-firm knowledge sharing and spillovers, and the existence/absence of a creative cosmopolitan social milieu. The regional level is, of course, variably constituted. International labour migration largely focuses on urban regions, especially in more developed economies, and this is mirrored in the following discussion. However, international labour migration also plays a role in rural regions - and sometimes a highly significant one as, for example, in seasonal agricultural work.

- The focus on the firm (understood as employer organizations of different types) follows from the central interest of this paper in commodified knowledge; it excludes, the role of knowledge transactions in, for example, the household sector or some areas of the social economy. 
There are, of course, other levels at which tacit knowledge transactions by migrants can be analyzed. For example, there is an argument for front-staging the individual in such analyses (Williams 2006). Migrant networks also shape opportunities for and barriers to knowledge sharing, and these are necessarily multi-level. However, the national, the regional and the firm levels are particularly useful for examining the social situatedness of knowledge transactions, as argued above.

These three levels of analysis are considered separately below. However, the paper concurs with Amin's (2002: 386) view that space, place, and time are co-constituted and folded together. The three levels are inter-related in complex ways. For example, the national level determines labour market entry conditions for migrants but, in turn, national regulation is shaped by the requirements of the corporate sector, or by the broader dictates of capital accumulation in particular regions (for example, the labour needs of London in relation to UK immigration policies). While migration intersects with local labour market dynamics at the regional level, these dynamics are constituted of individual firm behaviour and are shaped by national regulation. Finally, workplaces are critical domains wherein migrant knowledge is commodified, and tacit knowledge is shared amongst employees. But national employment and taxation laws shape firms' reliance on internal versus external labour market strategies, and hence international migrants.

\section{National (B)}

Although Gamlen (2005) argues that national territorial boundaries no longer delineate the extent of a nation's human capital (Gamlen 2005), the national remains an important site for international migration. As Smith (2005): 237) argues, the national state mediates migration because it is 'a repository of language, national cultures and state-centred projects' (p237). Here we focus on three national 'projects' that shape migration-knowledge transactions: immigration policies, employment policies, and the national innovation system.

Immigration policies. Immigration policies shape the migration channels that migrants utilize - illegal or legal, informal or formal - which impact on employment prospects (Nagel 2005). And whether, for example, individuals are employed in the informal sector, have been found a job by an employment agency, or are being relocated by parent companies, is highly significant for individual knowledge transactions. Of course, the effects of immigration policies are not autonomous of other policy domains (Sassen 2000), even if the fragmentation of state powers often leads to such policies being framed in relative isolation. Instead, immigration policies intersect with employment policies (see below), and state investment in human capital.

States face a fundamental decision: whether to invest in developing indigenous human capital, and knowledge (via collective expenditure on schools, universities etc), or to 'free ride' and 'import' these via migration (Straubhaar 2000: 17). Historically, most advanced capitalist economies fostered indigenous human capital, with varying degrees of effectiveness. In 
Europe, immigration was encouraged in the 1950s-1970s, especially relatively 'unskilled' workers to fill gaps in metropolitan labour markets, but with little explicit reference to knowledge. From the 1990s, there was a shift to more active and positive management of skilled labour migration (Mahroum 2001). In practice, however, immigration policies are polarised. Skilled immigration is facilitated alongside tighter regulation of unskilled migration, with the latter resulting in increases in irregular migration/asylum seeking (Jordan and Düvell 2002: 2). The first explicitly recognises migrants' role in tacit knowledge transactions, while the second effectively denies this.

Highly skilled migration policies have become less autonomous policy domains because, as Mahroum (1999: 189) argues: 'Nations increasingly view technology transfer as primarily a people-oriented phenomenon .... Immigration is thus becoming increasingly an inseparable segment of national technology policies'. The immigration policies adopted by states in pursuit of such objectives have been documented (McLaughlan and Salt 2002), demonstrating a generalized relaxation of barriers to skilled labour migration in the developed world. But, at the same time, there has been a persistent 'bricolage of territories with differentiated rights for different migrant groups' (Williams, 2001: 103). First, there are variations in the extent to which immigration policies specifically recognise knowledge. These mostly focus on skills which, given their intangible nature, means relying on qualifications, implicitly recognising technical rather than social skills (Reich 1991) and many forms of tacit knowledge, intuition, and emancipatory knowledge. Secondly, the recognition of knowledge is highly racialised and gendered, as particular jobs and countries are favoured in most immigration regimes (see Iredale 2005 on the UK health sector). In contrast, unskilled migrants are mostly valued for meeting shortages of low cost labour in particular sectors, such as hospitality and agriculture; essentially they are considered 'knowledge dupes'.

While immigration policies are significant mediators of tacit knowledge transactions, the power of the national state should not be overstated. Individual migrants exercise human agency in negotiating immigration policies. And immigration policies are at the intersection of a number of, often conflicting, interest groups within and outside the state (Jordan et al 2003). Moreover, economic issues related to international migration - including knowledge transactions - can only partly be addressed via immigration policy (Sassen 2000: 73).

Employment regulations also mediate utilisation of migrants' knowledge and skills. As with immigration policies, knowledge is usually assessed in employment regulations via the surrogate measure of educational qualifications. Obstacles to knowledge transactions are particularly strong where country-specific qualifications apply to particular jobs, for example in medicine, law and accountancy. However, these qualifications do not necessarily measure substantive knowledge differences: country specific skills are socially and politically constructed, and can be used to protect indigenous workers against competition from immigrant workers or, as Duvander (2001: 210-1) argues, 'to conceal intolerance for diversity'. 
Both the national state and a range of intermediate agencies, notably national professional associations, manage employment regulations. Health services have probably been most exhaustively researched. In the UK, for example, the accreditation of foreign qualifications by corporatist professional bodies, such as the Royal Colleges, have mediated the ability of migrants to obtain particular types of employment (Kofman and Raghuram (2005); this determines the recognition and utilization, as well as the acquisition, of knowledge. Recruitment practices also tend to channel immigrant nurses from particular countries into temporary and lower-order nursing posts (Hardill and McDonald 2000), which effectively constrains knowledge transfer

opportunities. One consequence is differentiation amongst immigrants: those educated in the host, as opposed to the origin, country will have comparative advantages in the recognition of country-specific knowledge.

Employment regulation does not only shape employment, and knowledge transactions, for higher-order professional migrants. For example, there is relatively limited employment of unregistered migrants in Scandinavia's tightly regulated labour markets, compared to their substantial irregular employment in 'unskilled' jobs in, for example, catering and hospitality in the UK (Hjarno 2003). These migrants face not only divergent employment conditions but also different opportunities to use and acquire knowledge in contrasting regulatory settings.

National innovation systems, understood as the capacity to facilitate innovation, also shape migrants' knowledge transasctions. The constitution of national innovation systems is contested (Hollingsworth 2000), but the key elements are relationships amongst firms and other organizations, including universities, public sector agencies, and financial bodies, as well as the general regulatory and institutional framework (Lundvall 1992). Debates about such systems pay scant attention to migration, but these shape migrants' knowledge transactions, while migrants can play significant roles in national innovation system.

The contribution of international migration is probably most obviously observed in the role of foreign scientists in research and development. This has been recognized as a driving force behind the strong R\&D performance of the USA (Regets 2001). But there is a two way relationship, because leading researchers, academics and students are attracted, above all, by key features of the national innovation system: a critical mass of knowledge excellence, possibilities to work with leading researchers, access to state of the art equipment, and meritocratic and transparent career and reward systems (NOP Business/Institute for Employment Studies 2002). Migrants are also attracted to work for individual firms, or a group of firms, in a knowledge community (see Henry and Pinch 2000 on the UK motor sport industry), and by the openness of cultures to external ideas, or their cosmopolitanism. Therefore, national innovation systems are 'folded' into the regional and firm levels, where many aspects of the infrastructures and cultures of knowledge are articulated. The next section of the paper considers the regional level. 


\section{Regional (B)}

The region is a key site for mediating relationships between migration and knowledge, especially via proximate inter-firm relationships, and as an (extrafirm) cultural setting. Amin and Thrift (1994) expressed the latter in terms of regions being a locus of cultural and institutional specificity - and this resonates with the concepts of encultured and embedded knowledge (Blackler 2002). These two factors are instrumental in shaping the attractiveness of a region for migrants, labour-market spillovers, and social networking, all of which shape migrants' knowledge transactions.

Clusters, collective learning and labour market spillovers. There is an extensive literature on spatial clustering which, arguably, provides three main economic benefits for firms: facilitating trust, an important prerequisite for knowledge sharing; increasing opportunities for sharing knowledge through face to face networking; and labour market spillovers, as workers move between firms, transferring knowledge. The learning regions literature has emphasised the importance of spatial propinquity in facilitating trust and social networking, enabling tacit knowledge sharing (Morgan 1997). We can restate that argument in terms of how spatial proximity, and sustained face-to-face contacts, can facilitate shared understandings of embedded and encultured knowledge, as a prelude to sharing technical and professional knowledge. But what is the role of migration in learning regions?

Most of the earlier writings on 'learning regions and cities' did not ascribe a role for migration, and it was left to Maskell and Malmberg (1999: 18) to make explicit an underlying negative assumption: 'If ... mobility is sufficiently low, the owners and managers of firms in most industries in a region or a small country will know each other either directly or indirectly'. In other words, migrants lack the encultured and embedded knowledge to be effective participants in these knowledge transactions. However, more recent commentaries have emphasized that clusters are a multiplicity of sites, characterised by both local and distanciated connections (Amin and Thrift 2002: 51-2). Moreover, the assumed relationship between trust and proximity has been questioned (Hess 2004: 175). Clusters do have localized advantages, what Storper and Venables (2002) termed the urbanization economies of 'buzz' (dense possibilities for face-to-face knowledge exchanges). However, Bathelt et al (2004) argued that 'pipelines' also channel external knowledge into local clusters. Of course, electronic communication is increasingly important in such connections (Amin 2002), but this paper has argued that corporeal co-presence, realized via international migration, remains an important 'pipeline' as, for example, Alaracon (1999) demonstrated in Silicon Valley.

Localised and distanciated tacit knowledge transactions are necessarily interlinked. Bathelt et al (2004) argued that information acquired through 'pipelines' can overspill to other firms via 'buzz'. Migrants may bring knowledge to firms that can overspill to other local firms, either through generalised labour turnover in the cluster (Keeble et al 1998: 20), or specifically through inter-firm mobility involving migrants. UK case studies 
(Henry and Pinch 2000; Lawton Smith and Waters 2005) empirically demonstrated the importance of high rates of localized labour market turnover in knowledge spillovers, but largely ignored links between migration and such spillovers. Yet, in-migration is generally strongest in dynamic urban regions and these, of course, are precisely the areas with high labour market turnover. Moreover, migrants may be attracted to regions with routinized high levels of labour turnover, being indicative of high levels of employment opportunities and reduced labour market precariousness. However, the attractiveness of regions to individual migrants is determined by more than intra- and inter-firm mobilities.

Culture, tolerance and diversity. Labour migrants have diverse motivations, including economic, cultural and lifestyle objectives. Of course, many labour migrants have narrowly economic objectives, including acquiring qualifications or skills (and associated knowledge), which have economic value in either the destination or the origin region. For them, engagement with the culture of the destination region is a necessary cost rather than a benefit (Hannerz 1996: 106). However, other migrants value 'openness' to cultural diversity and cosmopolitanism. This partly explains the greater relative importance of foreign-born engineers and scientists in Silicon Valley compared to Route 128, two major high tech clusters in the USA (Alarcon 1999).

There are differences in how cultural diversity is interpreted. Sassen (1998: xxxi) recognised the social and cultural diversity of large western cities, but also emphasised that corporate power inscribed many cultures and identities with 'otherness'. Her view was grounded in the persistent structural relationships that dominate major cities, and envisaged knowledge creation and transfer as being largely the preserve of elite migrants. Florida (2005: 36) was more positive and argued that the 'creative class', key players in knowledge creation and transfer, sought 'diversity of all kinds'. Migrants are attracted by, but also contribute to reproducing, diversity as a defining feature of dynamic and creative city regions. And diversity facilitates creativity and openness to knowledge transfers from migrants. In reality these are not so much competing views, as indicative of the contingent implications of cultural diversity for knowledge in different social settings.

Social and cultural diversity also has a negotiated set of meanings for individuals. It is very different for young professionals, actively creating 'boundaryless careers' (Arthur and Rousseau 1996) in, say, the cultural industries compared to transnational elites in financial and business services, let alone seasonal harvesting work. Cultural diversity is likely to be integral to those working in the culture industries, attracting them to particular cities. In contrast, transnational elites are more tightly focussed in their social and professional networking, and inhabit relatively smaller sub-sets of the cultural diversity of the city (Beaverstock 2004; 2005). Not all migrants have positive experiences of cultural diversity, as Sassen (1998) noted. Sociallydisadvantaged ethnic minorities may encounter 'blocked mobility' as employees, if their knowledge is not socially recognized (Bonacich and Modell 1980). In these circumstances, many turn to self-employment. Drawing on family and co-ethnic networks, they operate in selective niches requiring 
relatively narrow knowledge of markets and products (Waldinger et al 1990), and become isolated from the wider civil society (Markovitic and Manderson 2000) and therefore from the knowledge possibilities inherent in the city's creative cultural diversity. And we know little of the experiences of, say, seasonal harvest workers or kitchen staff in this respect, which underlines the importance of complementary workplace-level analyses.

\section{The workplace $(B)$}

If firms are ' ... repositories of competences, knowledge, and creativity, as sites of invention, innovation and learning' (Amin and Cohendet 2004: 2), how do firms 'harvest' the tacit knowledge of individual migrant workers? Firms face three challenge: recruiting individuals with appropriate knowledge; facilitating knowledge exchanges and co-learning amongst workers; and transferring knowledge to the firm level for redistribution. These pose distinct challenges in relation to migrant workers.

Recruitment. All migrants carry knowledge, and have learning capacities. However, recruiting migrants poses distinctive challenges for firms in respect of capturing tacit knowledge, and this can be addressed via Blackler's (2002) typology of knowledge. There are unlikely to be consistent differences between individual migrants and locals in respect of embodied and embrained knowledge, although educational and industrial structures in some countries may favour their development. Migrants and locals, however, have different embedded and encultured knowledge. Migrant workers, and firms, will usually incur costs as the former acquire country- or region-specific knowledge. Whether the costs are significant depends on the knowledge required for particular jobs in particular firms. Writing computer systems software, for example, may require relatively limited encultured knowledge compared to heading up a marketing team. Moreover, in some jobs migrants' distinctive encultured knowledge is highly valued by firms, and is reflected in their recruitment. Examples include tourist guides or receptionists providing services to co-national tour groups (Aitken and Hall 2000), and financial services professionals with knowledge of clients and contacts in other countries (McCall 1997). In these instances, corporeal mobility is essential for tacit knowledge transactions, and the challenge for recruitment practices is to recognize those migrants who can transfer or exercise such knowledge effectively.

In the most positive reading of recruitment, migrants may be valued as brokers, or boundary spanners, who can bridge different knowledge communities. This function is not exclusive to migrants and not all migrants have the ability and knowledge to perform this role effectively. However, international migrants potentially transfer knowledge of different products, processes, markets, and social networks. Beaverstock (2005), for example, reported on how such transfers, and associated learning, are valued in global financial services. In some sectors, companies may welcome mobility because knowledge spillovers resulting from migration and labour force turnover are seen as externalities enjoyed by all firms. This may lead to positive and open recruitment practices. But, in some industries, firms seek 
knowledge monopolies and may focus as much on limiting the mobility of existing workers as on recruiting new (migrant) workers.

Co-learning and knowledge sharing. Individual knowledge will have little impact on company performance unless shared with other individuals and groups (Nonaka and Takeuchi 1995). Firms need effective management strategies to harvest this knowledge. Although company-organised purposive learning channels facilitate this, most tacit knowledge transactions are informal (Ipe 2003: 349), and this has particular implications for international migrants.

Informal co-learning and knowledge sharing, between migrants and nonmigrants or other migrants, is also shaped by firm-level institutions, understood as: 'a common interpretative context based on the visions, values and memories in the form of artifacts, routines and experience which help to ensure that what each employee learns is in some way connected to what the other employees might know or learn' (Bathelt et al 2004: 34). But even where an institutional context is broadly favourable, it is not monolithic, and firms are sites of competing interests amongst individuals and groups (Schoenberger 1997). The most effective firms mobilize rather than tolerate such differences (Brown and Duguid 1991) including, we would argue, those arising from migrant status.

Migrants, like most newcomers to firms, begin in peripheral positions within work groups (Lave and Wenger 1991). Effective mobilization involves moving newcomers 'incrementally along a continuum from the domain of stranger toward that of friend' (English-Lucek et al 2002: 97). In part, this involves overcoming relational obstacles around race and nationality (Nagel 2005). It is also about social identities (Child and Rodrigues 2003), especially in respect of systemic and strategic (referred to in this paper as embedded and encultured), rather than technical, knowledge, as the former originate within organizations and are more identity-sensitive. The 'othering' of migrants, particularly ethnic minorities, generally obstructs knowledge sharing. It can be difficult to overcome such obstacles. For example, conscious attempts were made by potential boundary spanners in Japanese banks in London to deepen mutual understanding of each other's knowledge framework. However, these contacts mainly emphasized differences, and knowledge transactions remained truncated (Sakai 2000).

Migrants do bring their positionality and their social identities into the work place, and these mediate knowledge transactions. However, these are not given but, rather, are constantly being made and remade. In other words, migrants are not passive recipients of either positionalities or knowledgetransfer routines. Rather they act back upon and shape firm-level structures. Regional diversity and cosmopolitanism also shape relationships within firms, as well as the mobility of migrants between firms, which underlines the interfolding of different levels of analysis.

Migrants and knowledge management. While firms benefit from informal knowledge transactions between migrants and other workers, they also seek 
to manage such transactions across time and space. Dixon (2000) identified five main types of corporate knowledge transfers: serial, near, expert, far, and strategic. The last two are most likely to involve, in different forms, individual mobility. A 'far transfer' involves transferring tacit knowledge about nonroutine tasks from the team in which it originated to another team (wherever located). A 'strategic transfer' involves transferring complex knowledge between teams that are separated by both time and space. Tacit knowledge will be important in both, although combined with explicit knowledge in different ways.

Mobility, including migration, is implicated in two key company strategies for realising knowledge transfers. First, in epistemic communities (Amin and Cohendet 2004), individuals are brought together to work on particular projects (e.g. new products). Where companies have multiple branches, or inter-company collaboration is involved, this may require corporeal mobility, probably alongside virtual communication.

Secondly, multi-national companies may, irregularly or routinely, organize temporary migration of professional and managerial staff to effect knowledge transfers. This depends on the characteristics of the multi-national. Bartlett and Ghosal (1989) argued that it is central only to 'transnational' companies that view knowledge as dispersed, and seek to distribute this across the company, irrespective of where it originates. In such companies, managers expect to spend periods abroad, working in different subsidiaries, as essential to acquiring and distributing knowledge. McCall (1997) identified what managers learned from international postings: being more open minded and better able to deal with a broader range of people; tolerance of ambiguity; acquiring multiple perspectives; and ability to work with others (tolerating diversity, communicating more, and anticipating better the impact of one's practices). To differing degrees, these all chime with the notion of more cosmopolitan managerial perspectives, but the management literature pays scant attention to extra-work diversity. Of course not all intra-company migrants fit into this framework, and the main objective for engineers and technicians may be to transfer particular technical skills (see Williams et al 2004). And smaller firms, especially those focusing on domestic markets and supply chains, may attach little value to international experiences. However, the firm level is undoubtedly important for the analysis of knowledge transactions by migrants - but it is only one of a series of inter-folded levels.

\section{The multi-level folding of knowledge transactions (B)}

Although the three levels have been discussed separately, migrants' experiences of, and contribution to, knowledge transactions has to be seen in context of how these are, what Amin (2002) generically termed, 'folded together'. Immigration and employment laws are framed in response to competing interests within and outside the state, including those emanating from the EU, and national and regional political responses to both economic and diversity issues. In turn these policies shape local labour markets. National innovation systems are partly framed by legislation (for example, tax relief on $R \& D$ ) and state investment in scientific infrastructures, but it is also 
constituted of the regional and firm level institutions that facilitate knowledge transactions. The region is also a distinctive cultural system and migrants respond to, while their experiences are mediated by, the degree of openness and cosmopolitanism in such systems. Finally, firms increasingly are understood to have porous boundaries, so that the roles of migrants are shaped not only by corporate strategies but also by wider relationships that stretch beyond the individual firm, and which reflect and shape regional diversity, for example. Individual actors, institutions and structures in these different levels act on and back against each other, creating a shifting bricolage of migration-knowledge relationships. The ways in which levels are folded in on each other is, of course, time and place specific. Moreover, international migration increasingly differentiates places and is a significant driver of economic change.

This begs the question of 'so what is new - surely international migration has always effected knowledge transctions'. While this assertion is incontestable, changes in the nature of modern economies - tacit knowledge is increasingly important in the competitiveness of firms, regions and countries, while there have been quantitative and qualitative shifts in migration - have given additional significance to the relationships between migration and knowledge. The final section of the paper sets out some of the challenges facing researchers in developing a multi-level perspective on these relationships.

\section{CONCLUSIONS: RETHINKING INTERNATIONAL MIGRATION AND KNOWLEDGE}

This paper initially considered the lack of engagement between research on international migration and knowledge. The former has focussed far more on skills than knowledge, with notable exceptions such as transnational elites in world cities. In contrast, the latter - while recognising the importance of intra-, inter-, and extra-firm networks - has paid little attention to the role of corporeal mobility, let alone international migration, in knowledge transactions via these networks. There is also little research on the management specifically of migrant's tacit knowledge within companies. In response to this research gap, the paper has outlined a multi-level approach to analysing migrants' roles in knowledge transactions. The discussion has mainly been conceptual, while also drawing on fragmented empirical research in these domains.

Of course, the paper has only outlined a framework for conceptualising and analysing the role of migrants in knowledge transactions (see also Williams 2006). However, given the significance and diversity of both international migration and knowledge in modern economies, there is a compelling need for further theoretically-informed and -informing empirical research. In part, this would build on existing research on skills, human capital, competences, knowledge spillovers and knowledge management. But there is also a need for research that addresses centrally the key relationships between migration and knowledge transactions. 
First, there is a need to explore further the transfer of different types of knowledge via migration, and especially how these are economically valorised. This will require further conceptual refinement but above all the measurement of different forms of tacit knowledge, drawing on the management and psychology literatures (Sternberg 1995). The elusive nature of tacit knowledge means that much of the research will involve qualitative or ethnographic research, with detailed case studies of individual migrants and individual workplaces. However, a multi-level perspective will help contextualise such case studies.

Secondly, there is a need for a dynamic approach, especially in the key learning phases. The literatures on skills and human capital (Williams and Baláž 2005; Chiswick and Hatton 2003) suggest that many, if not most, migrants face significant learning curves in destination countries. And the knowledge literature emphasises the different types of knowledge that migrants transfer to, and acquire in, the destination. But we still know little about the steepness of most learning curves, other than in terms of language acquisition or the outcomes in terms of wage convergence (Dustmann 1994). There is a particular need to focus on the learning curves for embedded or encultured knowledge (Blackler 2002), as keys to unlocking understanding of the social situated learning and knowledge experiences of migrants.

Thirdly, while this paper has focussed on international migration, it needs to be studied in context of the relative importance of other channels of knowledge transactions. The starting point for such research is the debate on distanciated versus localised (in particular, proximity resulting from migration) relationships and networks (Amin 2002). Of course, these are not mutually exclusive, and the key question is how are different knowledge channels combined? Nonaka and Takeuchi (1995) have argued that codified and tacit knowledge are interwoven, and this paper stresses the need to consider how international migration is combined with other means of tacit, as well as codified, knowledge transactions. While recent research has focussed on the catalytic role of virtual communication, there is a need for further research on the substitutability of different forms of corporeal mobility (Salt and Ford 1993). For example, what types of knowledge, under what conditions, are transactable by meetings, compared to short-term placements, temporary or 'permanent' migration? And how are such transactions differently socially situated?

Fourthly, while the author has argued elsewhere (Williams 2005) that all migrants are potential knowledge carriers, the empirical research referenced in this paper indicates we know far more about 'elite' knowledge - whether in terms of migrants, places or industries - than the knowledge of so-called 'unskilled' migrants, and or those working in less knowledge intensive industries or places, such as harvesting crops in rural areas, serving fast food in inner cities, or changing bedding in tourist resorts. What types of knowledge transactions occur or do not occur in these situations, and what types of knowledge do migrants acquire. In the case of temporary and return migrants, this may only be fully revealed when individuals re-enter labour markets in countries of origin (Williams and Baláž 2005). It may only be in these 
situations that they can valorise the knowledge acquired abroad of another language, of contacts, or of different cultures and institutions. This underlines the time and place specificity of knowledge transactions, as well as their social -situatedness.

Finally, a multi-level perspective leads inevitably to the logic of comparative studies that analyse migration and tacit knowledge transactions in different national, regional and workplace settings. This would allow us to unravel some of the complexities of how different levels are enfolded, providing insights into both international migration and the transfer and management of knowledge.

\section{Acknowledgment}

The author gratefully acknowledges the support provided for this research by a British Academy Readership.

\section{REFERENCES (A)}

Aitken, C. and Hall, C.M. (2000) 'Migrant and foreign skills and their relevance to the tourism industry', Tourism Geographies: an International Journal of Place, Space and the Environment, 2, 66-86.

Alarcon, R. (1999) 'Recruitment processes among foreign-born engineers and scientists in Silicon Valley', American Behavioral Scientist, 42, 1382-97

Amin, A. (2000) 'Organisational learning through communities of practice', Paper presented at the Millennium Schumpeter Conference, University of Manchester 28 June-1 July.

Amin, A. (2002) 'Spatialities of globalization', Environment and Planning A, 34, 385-99

Amin, A. and Cohendet, P. (2004) Architectures of knowledge: firms, capacities and communities, Oxford: Oxford University Press

Amin, A. and Thrift, N. (1994) Globalization, institutions and regional development in Europe, Oxford: Oxford UP.

Amin., A. and Thrift, N. (2002) Cities: reimagining the urban, Cambridge: Polity Press.

Arthur, M. B. and Rousseau, D. M. (1996) The boundaryless career: a new employment principle for a new organizational era, New York: Oxford University Press.

Bartlett, C. A. and Ghosal, S. (1989) Managing across borders: the transnational solution, London: Century Business 
Bathelt, H., Malmberg, A. and Maskell, P. (2004) 'Clusters and knowledge: local buzz, global pipelines and the process of knowledge creation', Progress in Human Geography, 28, 31-56

Beaverstock, J. V. (2002) 'Transnational elites in global cities: British expatriates in Singapore's financial district' Geoforum, 33, 525-38

Beaverstock, J. V. (2004) 'Managing across border": knowledge management and expatriation in professional legal service firms; Journal of Economic Geography , 4, 157-79

Beaverstock, J. V. (2005) 'Transnational elites in the city: British highly-skilled inter-company transferees in New York City's financial district', Journal of Ethnic and Migration Studies, 31, 245-68

Beckett, D. (2000) 'Making workplace learning explicit: an epistemology of practice for the whole person', Westminster Studies in Education 23, 41-53

Bertels, T. and Savage, C. M. (1998) 'Tough questions on knowledge management', in Krogh, von G., Roos, J., and Kleine, D. (eds), Knowing in firms: understanding, managing, and measuring knowledge, London: Sage Publications, 7-25.

Blackler, F. (2002) 'Knowledge knowledge work and organizations', in C. W. Choo and N. Bontis (eds), The strategic management of intellectual capital and organizational knowledge, New York: Oxford University Press, 47-62.

Bonacich, E. and Modell, J. (1980, The economic basis of ethnic solidarity: small business in the Japanese American community, Berkeley: University of California Press

Brown, J. S. and Duguid, P. (1991) ' Organizational learning and communities-of-practice: towards a unified view of working, learning and innovation', Organizational Science, 2, 40-57

Bunnell, T. G. and Coe, N. M. (2001) 'Spaces and scales of innovation', Progress in Human Geography, 25, 569-89

Child, J. and Rodrigues, S. (2003), 'Social identity and organizational learning', in M. Easterby-Smith and M. A. Lyles (eds), The Blackwell handbook of organizational learning and knowledge, Oxford: Blackwell, 53555 .

Chiswick, B. R. and Hatton, T. J. (2003) 'International migration and the integration of labor markets', in M. Bordo, A. Taylor and J Williamson (eds), Globalization in historical perspective, Cambridge: National Bureau of Economic Research, 65-119 
Dixon, N. (2000) Common knowledge: how companies thrive by sharing what they know, Boston: Harvard Business School Press,

Dustmann, C. (1994) 'Speaking fluency, writing fluency and earnings of Migrants', Journal of Population Economics, 7, 133-56.

Dustmann, C., Fabbri, F., Preston, I., Wadsworth, J. (2003) Labour market performance of immigrants in the UK labour market, London: Home Office, Online Report 05/03.

Duvander, A-Z. E. (2001) 'Do country-specific skills lead to improved labor market positions? An analysis of unemployment and labor market returns to education among immigrants in Sweden', Work and Occupations, 28, 210-33

Easterby-Smith, M. and Lyles, M. A. (2003) 'Introduction: watersheds of organizational learning and knowledge management', in M. Easterby-Smith and M. A. Lyles (eds), The Blackwell handbook of organizational learning and knowledge, Oxford: Blackwell, 1-15.

English -Lucek, J. A., Darrah, C. N. and Saveri, A. (2002) 'Trusting strangers: work relationships in four high-tech communities', Information,

Communication and Society, 5, 90-108

Evans, K. (2002) 'The challenge of "making learning visible': problems and issues in recognizing tacit skills and key competences', in K. Evans, P. Hodkinson and L. Unwin (eds), Working to learn: transforming learning in the workplace, London: Kogan Page, 79-94

Findlay, A. F., Li, A. Jowett and R. Skeldon(1996) 'Skilled international migration and the global city: a study of expatriates in Hong Kong', Transactions of the Institute of British Geographers, 21, 49-61

Florida, R. (2005) Cities and the creative class, New York: Routledge

Gamlen, A. (2005) 'The brain drain is dead, long live the New Zealand Diaspora', Oxford: ESRC Centre on Migration, Policy and Society, Working Paper 10

Guarnizo, L. E. and Smith, M. P. (1998) 'The locations of transnationalism', in Smith, M. P. and Guarnizo, L. E. (eds), Transnationalism from below, New Brunswick: Transaction Publisher.

Hannerz, U. (1996) Transnational connections: culture, people, places, London: Routledge.

Hardill, I. And MacDonald, S. (2000) 'Skilled international migration: The experience of nurses in the UK', Regional Studies, 34, 681-92

Held, D. (ed.) (2000) A globalizing world? Culture, economics and politics, London: Routledge. 
Henry, N. and Pinch, S. (2000, 'Spatialising knowledge: placing the knowledge community of Motor Sport Valley', Geoforum, 31, 191-208

Hess, M. (2004) 'Spatial' relationships? Towards a reconceptualization of embeddedness', Progress in Human Geography, 28, 165-86

Hjarno, J. (2003) Illegal immigrants and development in employment in the labour markets of the EU, Aldershot: Ashgate.

Hodkinson, P., Hodkinson, H., Evans, K., Kersh, N., Fuller, A., Unwin, L. (2004) 'The significance of individual biography in workplace learning', Studies in the Education of Adults, 36, 6-24

Hollingsworth, J. R. (2000) 'Theme section: Doing institutional analysis: implications for the study of innovations', Review of International Political Economy, 7, 595-644

Hymer, S. H. (1960) The international operations of national firms: a study of direct foreign investment, Cambridge, MA.: MIT Press (thesis 1960; published1976).

Ipe, M. (2003) 'Knowledge sharing in organizations: a conceptual framework', Human Resource Development Review, 2, 337-59

Iredale, R. (2005) 'Gender, immigration policies and accreditation: valuing the skills of professional women migrants', Geoforum, 36, 155-66 Jordan, B. and Düvell, F. (2002) Irregular migration: the dilemmas of transnational mobility, Cheltenham: Edward Elgar.

Jordan, B., Stråth, B. and Triandafyllidou, A. (2003) 'Comparing cultures of discretion', Journal of Ethnic and Migration Studies, 29, 373-95

Keeble D., Lawson C., Lawton Smith H., Moore B. and Wilkinson F. (1998) Collective learning processes and inter-firm networking in innovative high technology regions, ESRC Centre for Business Research Working Paper 86

King, R. (2002) 'Towards a new map of European migration', International Journal of Population Geography, 8, 89-106.

Kloosterman, R. and Rath, J. (2001) 'Immigrant entrepreneurs in advanced economies: mixed embeddedness further explored', Journal of Ethnic and Migration Studies, 27, 189-201

Kofman, E. and Raghuram, P. (2005) 'Gender and skilled migrants: into and beyond the work place', Geoforum, 36, 149-54

Koser, K. and Salt, J. (1997) 'The geography of highly skilled international migration', International Journal of Population Geography, 3, 285-303 
Ladkin, A and Riley, M. (1996) 'Mobility and structure in the career paths of UK hotel managers: a labour market hybrid of the bureaucratic model?' Tourism Management, 17, 443-52.

Lave, J. and Wenger, E. (1991) Situated learning: legitimate peripheral participation, Cambridge: Cambridge University Press.

Lawton Smith, H. L. and Waters, R. (2005) 'Employment mobility in hightechnology agglomerations: the cases of Oxfordshire and Cambridgeshire', Area, 37, 189-98

Lucas, E. B. (2001) Diaspora and development: highly skilled migrants from East Asia, Report prepared for the World Bank

Lundvall, B. Ă . (ed.)(1992) National systems of innovation: towards a theory of innovation and interactive learning', London: Pinter.

McCall, M. (1997) High fliers, Boston: Harvard Business School Press.

McLaughlan, G. and Salt, J. (2002) Migration policies toward highly skilled foreign workers, London: University College London, Migration Research Unit, Report to the Home Office

Mahroum S. (1999) 'Highly skilled globetrotters', in OECD (ed), Mobilising human resources for innovation. Proceedings of the OECD workshop on science and technology labour markets. Paris: OECD.

Mahroum, S. (2001) 'Europe and the immigration of highly skilled labour', International Migration, 39, 27-43

Markovitic, M. and Manderson, L. (2000) 'European immigrants and the Australian labour market: a case study of women from the former Yugoslavia', Journal of Ethnic and Migration Studies, 26, 127-36

Maskell, P. and Malmberg, A. (1999) 'Localised learning and industrial competitiveness', Cambridge Journal of Economics, 23, 167-85

Massey, D. (1994) Place, space and gender, Minneapolis: University of Minnesota Press.

Meyer, J.-B. (2001) 'Network approach versus brain drain: lessons from the diaspora', International Migration, 39, 91-110

Morgan, K. (1997) 'The learning region: institutions, innovation and regional renewal', Regional Studies, 31, 491-503

Nagel, C. (2005) 'Skilled migration in global cities from 'Other' perspectives: British Arabs, identity politics, and local embeddedness', Geoforum, 36, 197210 
Nohria, N. and Ghoshal, S. (1997) The differentiated network, San Francisco: Jossesy-Bass.

Nonaka, I. and Takeuchi, H. (1995) The knowledge creating company: how the Japanese companies create the dynamics of innovation, New York: Oxford University Press.

NOP Business/Institute for Employment Studies (2002) Knowledge migrants the motivations and experiences of professionals in the UK on work permits: Final report, London: Home Office and Department of Trade and Industry

Payne, J. (2000) 'The unbearable lightness of skill: the changing meaning of skill in UK policy discourses and some implications for education and training', Journal of Education Policy, 15, 353-69

Polanyi, M. (1966) The tacit dimension. London: Routledge and Kegan Paul.

Raghuram, P. (2004) 'The difference that skills make: gender, family migration strategies and regulated labour markets', Journal of Ethnic and Migration, Studies, 30, 303-21

Regets. M. (2001) Research and policy issues in high-skilled international migration: a perspective with data from the United States, National Science Foundation Discussion Paper No. 366, Arlington and IZA, Bonn, September 2001

Reich, R. (1991) The work of nations: preparing ourselves for $21^{\text {st }}$-Century capitalism, London: Simon and Schuster.

Sakai, J. (2000) The clash of economic cultures: Japanese bankers in the City of London, New Brunswick: Transaction Publisher.

Salt, J. and Findlay, A. (1989) 'International migration of highly skilled manpower: theoretical and development issues', in R. Appleyard (ed) The impact of international migration on developing countries, Paris: OECD, 10928

Salt, J. and Ford, R. (1993) 'Skilled international migration in Europe: the shape of things to come?', in R. King (ed), Mass migration in Europe, London: Belhaven, 293-309

Sassen. S. (1998) Globalization and its discontents, New York: The New Press.

Sassen, S. (2000) 'Regulating immigration in a global age: A new policy landscape', Annals of the American Academy (AAPPS), 570, 65-77

Schoenberger, E. (1997) The cultural crisis of the firm, Oxford: Blackwell. 
Sjastaad, L. A. (1962) The costs and returns of human migration, Journal of Political Economy, 70, 80-93.

Smith, M. P. (2005) 'Transnational urbanism revisited', Journal of Ethnic and Migration Studies, 31, 235-44

Sternberg, R., (1995) 'Theory and management of tacit knowledge as a part of practical intelligence', Zeitschrift für Psychologie, 203, 319 - 34

Storper, M. and Venables, A.J. (2002) Buzz: the economic force of the city. Paper presented at the DRUID Summer Conference on 'Industrial Dynamics of the New and Old Economy - Who is Embracing Whom?', Copenhagen, Elsinore, 6-8 June. Quoted in Bathelt et al 2004.

Straubhaar, T. (2000) International mobility of the highly skilled: brain gain, brain drain or brain exchange, Hamburg: Hamburg Institute of International Economics, Discussion paper 88.

Styhre, A. (2004) 'Rethinking knowledge: a Bergsonian critique of the notion of tacit knowledge', British Journal of Management, 15, 177-88

Thrift, N. (1996) Spatial formations . London: Sage.

Waldinger, R., Aldrich, H. and Ward, R. (1990) 'Opportunities, group characteristics, and strategies', in R. Waldinger, H. Aldrich and R. Ward (eds), Ethnic entrepreneurs, Sage, Newbury Park, 13-48.

Ward, K. (2004) 'Going global? Internationalisation and diversification in the temporary staffing industry', Journal of Economic Geography, 4, 251-73.

Wenger, E. (2000) 'Communities of practice and social learning systems', Organizations, 7, 225-46

Williams, A., (2001) 'New Forms of International Migration: in Search of Which Europe', in H. Wallace (ed), Interlocking dimensions of European integration, Basingstoke: Palgrave, 103-21.

Williams, A. M. (2005) International migration and knowledge, Oxford: Oxford University, Centre on Migration, Policy and Society, Working Paper 17.

Williams, A. M. (2006, in press) 'International migration, learning and knowledge', Progress in Human Geography.

Williams, A. M. and Baláž, V. (2005) 'What human capital, which migrants? Returned skilled migration to Slovakia from the UK', International Migration Review, 39, 439-68 
Williams, A. M., Baláž, V. and Wallace, C. (2004) 'International labour mobility and uneven regional development in Europe: human capital, knowledge and entrepreneurship', European Urban and Regional Studies, 11, 27-46

Yang, B. (2003) 'Toward a holistic theory of knowledge and adult learning', Human Resource Development Review, 2, 106-29 